\title{
Normal deglutitive responses of the human lower oesophageal sphincter
}

\author{
MICHAEL D. KAYE AND J. PHILIP SHOWALTER \\ From the University of Colorado Medical Center, Division of Gastroenterology, Department of Medicine, \\ Denver, Colorado
}

SUMMARY The responses to deglutition of the lower oesophageal high pressure zone were studied in 13 healthy subjects. The recording assembly included three perfused pressure recording catheters, whose recording orifices were at the same axial level, and a more distally situated $p \mathrm{H}$ electrode. Relaxation and contraction progressed in a sequential fashion along the length of the high pressure zone. At the time of maximum relaxation, a small pressure gradient, which was greatest at a point approximately $1 \mathrm{~cm}$ distal to the pressure inversion point, was maintained between stomach and oesophagus. The frequency of post-deglutitive contractions in the high pressure zone, which were observed to occur distal to the pressure inversion point in all subjects, steadily increased as the recording assembly was withdrawn proximally. The amplitude of such contractions was greater in the high pressure zone than in the distal oesophagus. There was a significant correlation between maximum resting pressure and amplitude of contractions within the high pressure zone. The proper assessment of the function of the high pressure zone should include consideration of the spatiotemporal relationships of pressure events within the lower oesophagus and the high pressure zone, in addition to measurements of their absolute dimensions.

The $p \mathrm{H}$ electrode measurements, performed after the intragastric instillation of at least $150 \mathrm{ml}$ of $0 \cdot 1 \mathrm{~N} \mathrm{HCl}$, showed transient falls in the $p \mathrm{H}$ of the distal high pressure zone after deglutition in all subjects. These $p \mathrm{H}$ responses decreased in frequency as the $p \mathrm{H}$ electrode was withdrawn proximally, and did not occur in the non-sphincteric oesophagus. It would appear therefore that although gastroesophageal competence is retained during swallowing, the mucosal lining of the greater part of the high pressure zone is briefly exposed to gastric contents for a few seconds after deglutition.

The existence of a physiological sphincter at the lower end of the oesophagus is well established. This sphincter is readily detectable by manometry as a zone of high pressure interposed between stomach and oesophagus (Fyke, Code, and Schlegel, 1956; Atkinson, Edwards, Honour, and Rowlands, 1957; Botha, Astley, and Carré, 1957). The normal response of the high pressure zone to deglutition is relaxation, that is to say, a transient decrease in pressure (Fyke et al, 1956; Botha et al, 1957; Kelley, Wilbur, Schlegel, and Code, 1960). In the more proximal part of the high pressure zone, relaxation is followed by contraction, which is of greater duration than that in the oesophagus (Fyke et al, 1956; Wilbur et al, 1960). Sphincteric relaxation and contraction are integral parts of the overall oesophageal motor response to swallowing. Thus, in Received for publication 8 February 1972. health, sphincteric contraction represents distal progression of the oesophageal peristaltic wave, and is preceded by the phase of relaxation. Since resting pressure in the stomach is higher than that in the oesophagus, it is theoretically possible that part or all of the mucosal lining of the lower oesophageal sphincter might be temporarily exposed to gastric contents after swallowing.

In normal individuals, the high pressure zone is several centimetres long. The exact length in a given individual varies according to the type of pressure sensor used (Code and Schlegel, 1958). It is pertinent to consider whether the high pressure zone, in response to deglutition, functions as a single unit, or, alternatively, whether relaxation and contraction pass through this zone in a progressive fashion. Support for the latter possibility was provided by Kelley et al (1960), who studied these phenomena 
with unperfused catheters and with a miniature balloon-covered oesophageal transducer.

It has been clearly shown that perfusion of a recording catheter improves the accuracy of pressure measurements in the high pressure zone (Pope, 1967; Winans and Harris, 1967; Pert, Davidson, Almy, and Sleisenger, 1959), and perfused recording systems are now used widely for recording oesophageal motility. In this study, the deglutitive responses at the various levels of the high pressure zone were re-examined with such a system; and since the manometric characteristics of the high pressure zone depend in part upon the radial orientation of the recording orifice (Kaye and Showalter, 1971), simultaneous observations were made with three recording catheters whose orifices were located at the same axial level. These measurements were combined with $p \mathrm{H}$ electrode determinations of the competence of the high pressure zone.

\section{Subjects and Methods}

Thirteen healthy subjects, 11 male and two female, and all either physicians or laboratory technicians, were studied. Their ages ranged from 23 to 39 years, with a mean of 31 . With the exception of one subject who suffered heartburn after drinking alcohol, and in whom an upper gastrointestinal series was normal, the group was entirely free of oesophageal symptoms. The recording assembly consisted of a centrally located $p \mathrm{H}$ recording lead, along the length of which were glued four stiff polyvinyl catheters (ID $1 \cdot 12$ $\mathrm{mm}$, OD $1.65 \mathrm{~mm}$ ), three for recording pressure and one for infusion. The recording catheters had lateral orifices, 1.60 by $2.30 \mathrm{~mm}$ in diameter, which were located at the same axial level, and which were equidistant around the circumference of a circle. The infusion tube had several lateral openings, the most proximal of which was $0.5 \mathrm{~cm}$ distal to the recording orifices. The $p \mathrm{H}$ electrode (Radiometer, Copenhagen, GI $282 \mathrm{C} / \mathrm{O}$ ) was located $5 \mathrm{~cm}$ distal to the recording orifices.

Studies were performed after an overnight fast. The recording assembly was passed through the mouth into the stomach, without premedication or pharyngeal anaesthesia. During recording, subjects lay supine on a couch, whose height was such that transducers and oesophagus were at approximately the same level. Recording catheters were connected through external transducers (Stratham $P_{23} \mathrm{De}$ ) to an ink-writing multichannel recorder (Gilson Macropolygraph). Respiration and swallowing were recorded by means of flexible pneumatic cuffs, positioned around the abdomen and neck, and connected to a fourth transducer. Transducers were calibrated by external standardization immediately before each study. Each recording catheter was continuously perfused with distilled water at a rate of $8.4 \mu \mathrm{l} / \mathrm{sec}$ by means of a constant infusion pump (Harvard Apparatus Co. Inc., Model 975). The $p \mathrm{H}$ was continuously monitored by a $p \mathrm{H}$ meter (Radiometer, Copenhagen, Type PHM 26) connected to the multichannel recorder by a servo linkage.

At least $150 \mathrm{ml}$ of $0 \cdot 1 \mathrm{~N} \mathrm{HCl}$ was introduced into the stomach through the infusion tube. The recording assembly was then withdrawn from stomach to oesophagus, $0.5 \mathrm{~cm}$ at a time. It was maintained at each level until the baseline pressure was stable, after which the manometric response to at least one 'dry' swallow was recorded. Stepwise withdrawal was continued until the most terminal portion of the recording assembly, that is the $p \mathrm{H}$ electrode, had completely traversed the high pressure zone. Hence, in each subject, measurements of the manometric responses to deglutition at the various levels of the high pressure zone, determined by three perfused catheters recording simultaneously from the same axial level, were complemented by observations on changes in $p \mathrm{H}$ within the high pressure zone following deglutition.

Resting high pressure zone pressures were measured in expiration, and expressed in relation to the gastric fundic end-expiratory baseline pressure. Changes in high pressure zone and oesophageal pressure after deglutition were expressed in relation both to the gastric baseline pressure and the resting pressure at each level. Onset and end of relaxation were defined, respectively, as the time intervals after deglutition when the expiratory pressure first fell below baseline and returned to baseline. Maximum relaxation was the lowest expiratory pressure during relaxation. Onset and end of contractions were similarly defined in relation to the baseline expiratory pressures at a given level. Maximum contraction was the highest expiratory pressure during contraction when the pressure wave showed fluctuations synchronous with respiration, and the peak pressure, irrespective of respiratory phase, when the pressure wave did not so fluctuate.

The pressure inversion point was used as a reference point for expression of axial levels within the high pressure zone and oesophagus. In several subjects, in whom the pressure inversion point did not occur at the same level in all three leads, each catheter was considered independently, and measurements were expressed in relation to the pressure inversion point recorded by that same catheter.

To examine the relationship between axial level within the high pressure zone and the various parameters of relaxation (onset, end, duration, and time of maximum relaxation) and contraction (onset and time of maximum contraction), the regression of 
each variable on axial level was calculated for each subject. From the individual slopes, a mean slope for each variable was obtained. The significance of the difference of the mean slopes from zero was determined by the one-tailed $t$ test.

\section{Results}

In order to present mean values for the whole group, it was necessary to choose a reference point in relation to which measurements from different individuals could be expressed. In the absence of a better alternative, the pressure inversion point was chosen for this purpose. Since three pressure records from each of 13 subjects were analysed, a maximum of 39 observations for a given measurement was available. However, the length of the high pressure zone varied considerably in different individuals (from 2 to $7 \mathrm{~cm}$ ) so that there was a progressive decrease in the number of observations in relation to the distance above or below the pressure inversion point. For this reason, presentation of data based upon mean values for the whole group reflects only those points within the high pressure zone at which an adequate number of observations was available.

\section{RELAXATION IN HIGH PRESSURE ZONE}

In all subjects, relaxation occurred regularly in all parts of the high pressure zone after deglutition. Very occasionally, relaxation was not observed in the most distal portions of the high pressure zone, where the resting pressure was only slightly elevated above the gastric baseline pressure.

The overall results pertaining to relaxation are shown in Table I. By all criteria, relaxation was an axially sequential phenomenon. Thus, the time intervals after deglutition for onset of relaxation, maximum relaxation, and end of relaxation, were

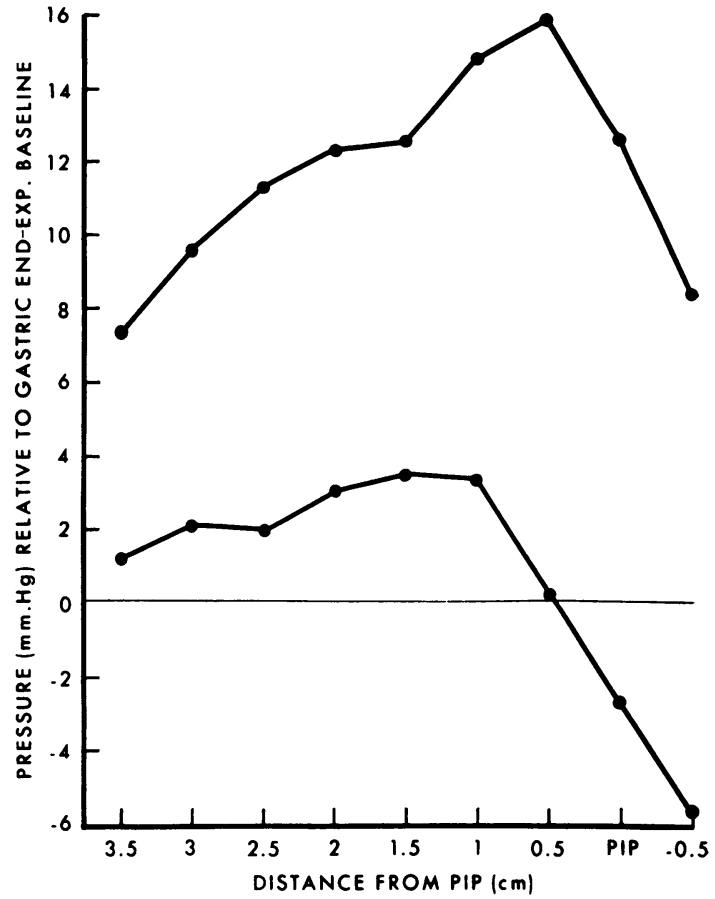

Fig. 1 Pressures at the different levels at times of maximum relaxation.

The upper line represents resting pressures. The lower line represents the lowest expiratory pressures recorded during relaxation. All measurements are expressed in relation to the pressure inversion point, with negative values $(-)$ on the horizontal axis denoting points proximal to it. Mean values, 13 subjects.

relatively long in the distal part of the high pressure zone-being, respectively, $3.33,7.84$, and 12.28 seconds, $2.5 \mathrm{~cm}$ below the pressure inversion point-

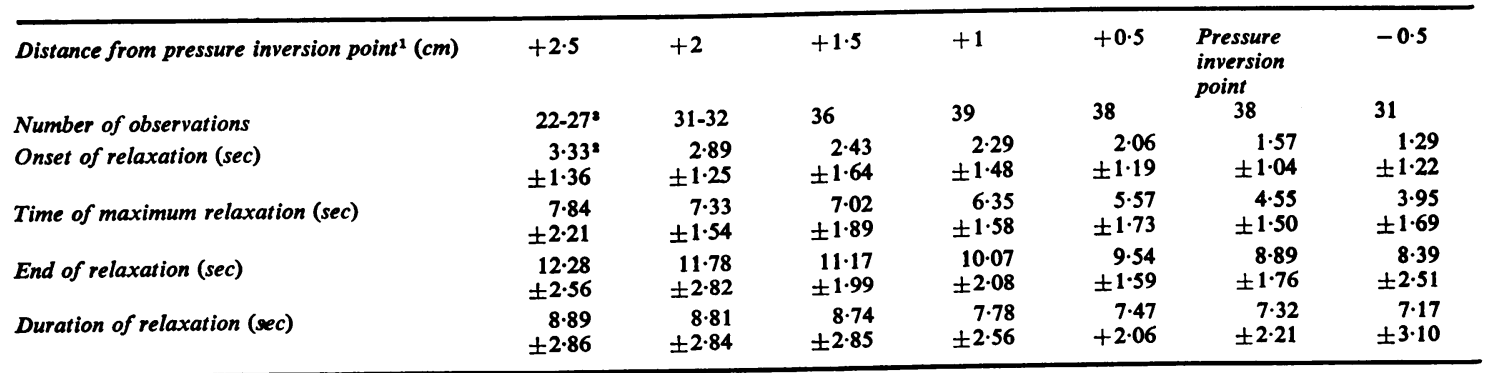

Table I The characteristics of relaxation at different levels within the lower oesophageal high pressure zone

1 In this and subsequent tables, high pressure zone levels are expressed in relation to the pressure inversion point. Positive values $(t)$ represent points caudad to it, whilst negative values $(-)$ are orad.

'Figures indicate means $\pm 1 \mathrm{~S} \mathrm{D}$.

The end of relaxation could not always be determined with accuracy in the distal part of the high pressure zone. The number of observations for end of relaxation and duration of relaxation is therefore smaller than that for the other two parameters. 
and decreased progressively to values of $1.29,3.95$, and 8.39 seconds $0.5 \mathrm{~cm}$ above the pressure inversion point. This trend was highly significant $(P<0.005)$ for each variable. The duration of relaxation decreased similarly $(P<0.05)$. During relaxation, pressures in the high pressure zone fell to levels close to the gastric end-expiratory baseline pressure. However, as illustrated in Fig. 1, which compares resting pressure throughout the high pressure zone with the lowest pressures measured during relaxation, the pressure barrier between stomach and oesophagus was not entirely abolished at most levels of the high pressure zone during relaxation. In the most distal part of the high pressure zone, pressure during relaxation was equal to, or only slightly greater than, gastric baseline in all subjects. In the most proximal portion of the high pressure zone, that is to say at and above the pressure inversion point, pressure fell below the gastric baseline to levels which approximated the oesophageal end-expiratory baseline pressures. Between these two extremes of the high pressure zone, there was, during relaxation, a gradient of pressure which was at its maximum between 1 and $1.5 \mathrm{~cm}$ below the pressure inversion point. It is evident from Fig. 1 that the pressure fall during relaxation was not proportional to resting pressure at a given point within the high pressure zone.

\section{HIGH PRESSURE ZONE CONTRACTION}

It was often difficult to determine with accuracy the end of a high pressure zone contraction, since the baseline pressure following contraction was frequently different from that which preceded contraction. Slight cephalad movement during swallowing of the tube complex relative to the lower oesophageal sphincter may account for this finding, since the postcontraction baseline tended to be higher in the distal and lower in the proximal high pressure zone. For this reason, mean values for the time intervals between deglutition and the completion of high pressure zone contraction, and for its duration, have not been included in Table II, which summarizes measurements for contraction in the high pressure zone and distal oesophagus. In accordance with other reports (Fyke et al, 1956; Kelley et al, 1960) high pressure zone contractions were relatively prolonged, the maximum recorded (and measurable) values being between 13.8 and 33.0 seconds (mean $20.7 \mathrm{sec}$ ) in the 13 subjects; and in general, the more distal the point of measurement, the greater the duration. The mean duration of 171 analysable contractions from the 13 subjects was 13.01 seconds. Contractions showed a peristaltic progression from distal oesophagus through the high pressure zone. Thus the time intervals between deglutition and onset of contraction and maximum contraction progressively increased from 4.9 and 9.9 seconds respectively at a point $2 \mathrm{~cm}$ above the pressure inversion point to 12.0 and 18.0 seconds $2 \mathrm{~cm}$ below the pressure inversion point. This trend was highly significant $(P<0.005)$. The amplitude of contractions, expressed in relation to the resting pressure at a given level, gradually increased from a mean value of $13.6 \mathrm{~mm} \mathrm{Hg}$ at a point $2 \mathrm{~cm}$ below the pressure inversion point to one of approximately $29 \mathrm{~mm} \mathrm{Hg}$ in the distal oesophagus. However, when measured relative to a single baseline, the gastric end-expiratory pressure amplitude was fairly constant throughout the whole of the high pressure zone, and relatively decreased in the distal oesophagus. Hence, the maximum pressures generated after deglutition were higher in the high pressure zone than in the distal oesophagus. The frequency of high pressure zone

\begin{tabular}{|c|c|c|c|c|c|c|c|c|c|c|c|c|}
\hline $\begin{array}{l}\text { Distance from pressure } \\
\text { inversion point }(\mathrm{cm})\end{array}$ & $+3 \cdot 5$ & +3 & $+2 \cdot 5$ & +2 & $+1 \cdot 5$ & +1 & +0.5 & & -0.5 & -1 & $-1 \cdot 5$ & -2 \\
\hline Number of observations & & & & 16 & 22 & 31 & 37 & 39 & 37 & 36 & 38 & 37 \\
\hline $\begin{array}{l}\text { Amplitude of contraction } \\
\text { (above preexisting base-line, }{ }^{1} \\
m m \mathrm{Hg} \text { ) }\end{array}$ & & & & $\begin{array}{l}13.6^{2} \\
\pm 8.7\end{array}$ & $\begin{array}{r}17 \cdot 1 \\
\pm 10.3\end{array}$ & $\begin{array}{r}20.0 \\
\pm 12.2\end{array}$ & $\begin{array}{r}20 \cdot 0 \\
\pm 9 \cdot 8\end{array}$ & $\begin{array}{r}20 \cdot 5 \\
\pm 9 \cdot 1\end{array}$ & $\begin{array}{r}24 \cdot 2 \\
\pm 10 \cdot 7\end{array}$ & $\begin{array}{r}29 \cdot 2 \\
\pm 11 \cdot 8\end{array}$ & $\begin{array}{r}29 \cdot 8 \\
\pm 9.8\end{array}$ & $\begin{array}{r}29 \cdot 0 \\
\pm 9 \cdot 7\end{array}$ \\
\hline $\begin{array}{l}\text { Amplitude of contraction } \\
\text { (above gastric baseline, } \\
\text { mm Hg) }\end{array}$ & & & & $\begin{array}{r}30.6 \\
\pm 18.9\end{array}$ & $\begin{array}{r}30 \cdot 7 \\
\pm 18 \cdot 1\end{array}$ & $\begin{array}{r}33 \cdot 7 \\
\pm 12 \cdot 5\end{array}$ & $\begin{array}{r}34 \cdot 4 \\
\pm 12 \cdot 3\end{array}$ & $\begin{array}{l}32 \cdot 8 \\
\pm 9 \cdot 0\end{array}$ & $\begin{array}{r}29 \cdot 5 \\
\pm 11 \cdot 3\end{array}$ & $\begin{array}{l}31 \cdot 3 \\
\pm 8 \cdot 8\end{array}$ & $\begin{array}{l}28.9 \\
\pm 9 \cdot 8\end{array}$ & $\begin{array}{l}24 \cdot 8 \\
\pm 8 \cdot 9\end{array}$ \\
\hline Onset of contraction (sec) & & & & $\begin{array}{r}12 \cdot 0 \\
\pm 3.8\end{array}$ & $\begin{array}{r}10 \cdot 5 \\
\pm 1.6\end{array}$ & $\begin{array}{r}9 \cdot 4 \\
\pm 1 \cdot 7\end{array}$ & $\begin{array}{r}9 \cdot 3 \\
\pm 1.4\end{array}$ & $\begin{array}{r}8.8 \\
\pm 1.9\end{array}$ & $\begin{array}{r}7 \cdot 8 \\
\pm 2 \cdot 3\end{array}$ & $\begin{array}{r}6 \cdot 2 \\
\pm 2 \cdot 1\end{array}$ & $\begin{array}{r}5 \cdot 6 \\
\pm 1.6\end{array}$ & $\begin{array}{r}4.9 \\
\pm 1.5\end{array}$ \\
\hline $\begin{array}{l}\text { Time of maximum } \\
\text { contraction }(\mathrm{sec})\end{array}$ & & & & $\begin{array}{r}18 \cdot 0 \\
\pm 4 \cdot 8\end{array}$ & $\begin{array}{r}15 \cdot 8 \\
\pm 1 \cdot 9\end{array}$ & $\begin{array}{r}15 \cdot 3 \\
\pm 2.9\end{array}$ & $\begin{array}{r}13.9 \\
\pm 1.4\end{array}$ & $\begin{array}{r}13 \cdot 6 \\
\pm 2 \cdot 3\end{array}$ & $\begin{array}{r}12 \cdot 1 \\
\pm 2 \cdot 3\end{array}$ & $\begin{array}{r}11 \cdot 6 \\
\pm 2 \cdot 4\end{array}$ & $\begin{array}{r}10 \cdot 7 \\
\pm 2 \cdot 2\end{array}$ & $\begin{array}{r}9.9 \\
\pm 2.0\end{array}$ \\
\hline $\begin{array}{l}\text { Frequency of contraction } \\
\text { (at sites of relaxation } \% \text { ) }\end{array}$ & $\begin{array}{l}4 / 14 \\
(28 \cdot 6)\end{array}$ & $\begin{array}{l}7 / 17 \\
(41 \cdot 2)\end{array}$ & $\begin{array}{l}10 / 23 \\
(43 \cdot 5)\end{array}$ & $\begin{array}{l}16 / 29 \\
(55 \cdot 2)\end{array}$ & $\begin{array}{l}22 / 36 \\
(61 \cdot 1)\end{array}$ & $\begin{array}{l}31 / 39 \\
(79 \cdot 5)\end{array}$ & $\begin{array}{l}37 / 39 \\
(94.9)\end{array}$ & $\begin{array}{l}38 / 38 \\
(100 \%)\end{array}$ & $\begin{array}{l}28 / 28 \\
(100 \%)\end{array}$ & & & \\
\hline
\end{tabular}

Table II The characteristics of contraction at different levels within the high pressure zone 'Preexisting baseline' refers, at any given level, to resting end-expiratory pressure, measured in relation to gastric baseline pressure. 'Figures indicate means $\pm 1 \mathrm{SD}$. 
contractions, expressed in relation to the number of relaxations observed at each point within the high pressure zone, and also shown in Table II, increased gradually from a value of $28.6 \%$ at a point $3.5 \mathrm{~cm}$ below the pressure inversion point to $100 \%$ at the level of the pressure inversion point. It is important to stress that in all subjects, contractions were observed at sites distal to the pressure inversion point. Contractions in the high pressure zone did not occur without prior relaxation. A representative tracing which illustrates normal sphincteric responses to deglutition at the different high pressure zone levels is shown in Figure 2.

Examination of the relationship between maximum resting pressure and the amplitude of high pressure zone contractions revealed a significant correlation between these two variables. Maximum resting pressure can be expressed either as the greatest mean value from the three recording catheters at a single point within the high pressure zone (maximal mean), or as the mean of the greatest values recorded by each of the three catheters, irrespective of high pressure zone level (mean maximum). The amplitude of high pressure zone contraction can be expressed either in relation to the preexisting baseline pressure at the site where contraction occurred, or in relation to the gastric end-expiratory pressure. From these measurements, values for maximum amplitude of high pressure zone contraction, and for the mean amplitude of all recorded high pressure zone contractions, can be obtained. Correlations between the two variables, according to these different modes of expression, are shown in Table III. The relationship between mean maximum resting high pressure zone pressure and mean amplitude of high pressure zone contractions is shown in Figure 3.

pH CHANGES IN THE HIGH PRESSURE ZONE In all subjects, the baseline $p \mathrm{H}$ level steadily increased on stepwise withdrawal of the $p \mathrm{H}$ electrode from stomach to oesophagus. The mean values for $p \mathrm{H}$ at the different levels of the high pressure zone,

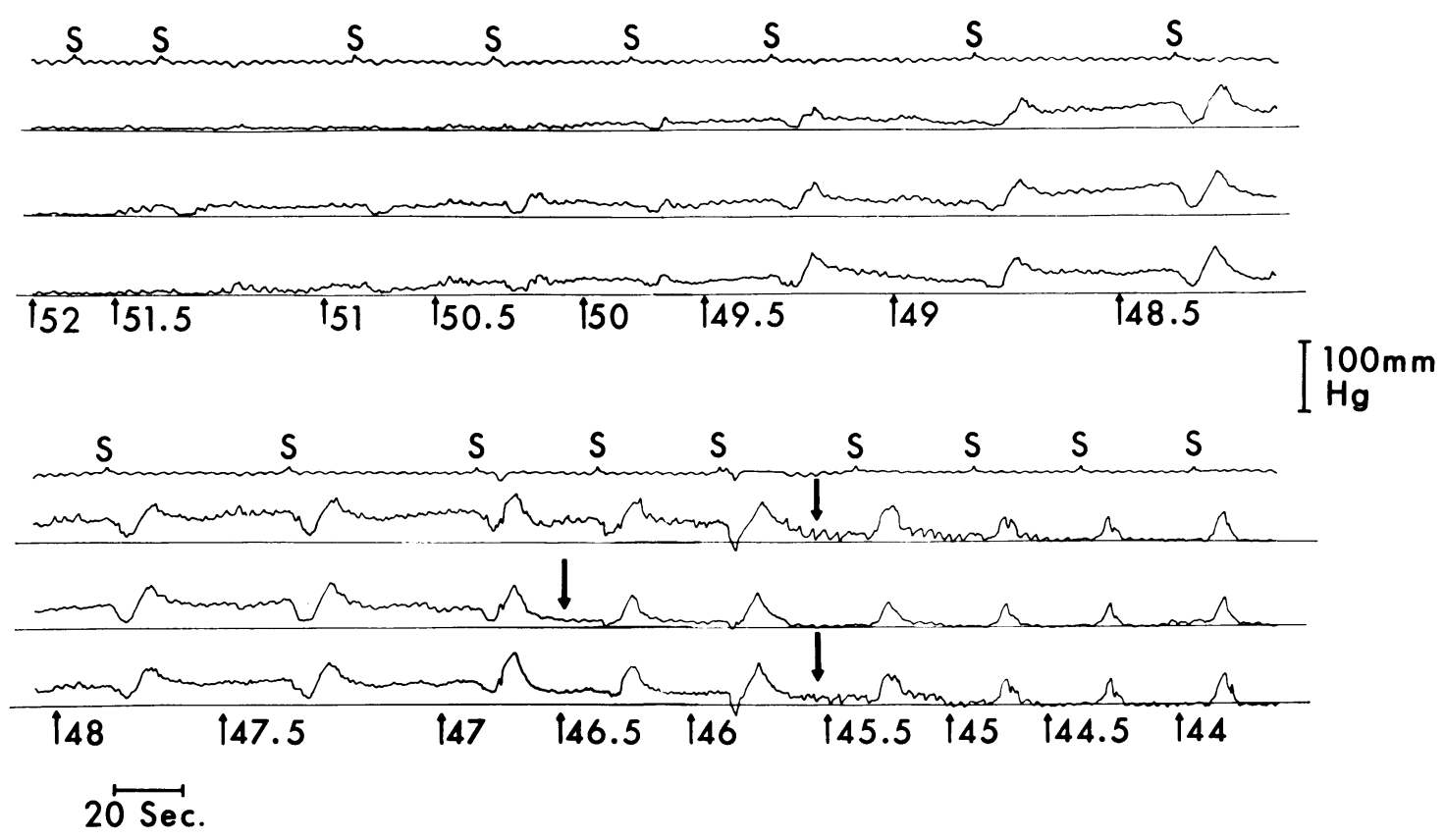

Fig. 2 Tracing to illustrate postdeglutitive responses of the high pressure zone. Normal male, aged 28.

The upper trace is a pneumograph, with inspiration shown as a downward deflection. The three lower traces are from perfused catheters, the openings of which are at the same axial level. The horizontal lines represent gastric endexpiratory baseline pressure. The numbers denote distances, in centimetres, between incisors and recording openings. Proximal withdrawal of the recording assembly is indicated by upward-pointing arrows. Points of respiratory reversal are shown by the downward-pointing arrows. ' $S$ ' denotes swallow.

(1) Post-deglutitive relaxations occur regularly at all levels. (2) High pressure zone pressure during relaxation is greatest in the mid-part of the zone, and (3) post-deglutitive contractions are seen in all leads at sites which are several centimetres distal to the pressure inversion point. 


\section{High}

Pressure

Zone

Resting

Pressure

Contraction Pressure

\begin{tabular}{|c|c|c|c|c|c|}
\hline \multicolumn{3}{|c|}{$\begin{array}{l}\text { Above Preexisting } \\
\text { Baseline }\end{array}$} & \multicolumn{3}{|c|}{ Above Gastric Baseline } \\
\hline $\begin{array}{l}\text { Maxi- } \\
\text { mum } \\
\text { Mean }\end{array}$ & $\begin{array}{l}\text { Mean } \\
\text { Maxi- } \\
\text { mum }\end{array}$ & $\begin{array}{l}\text { Overall } \\
\text { Mean }\end{array}$ & $\begin{array}{l}\text { Maxi- } \\
\text { Mean }\end{array}$ & $\begin{array}{l}\text { Mean } \\
\text { Maxi- } \\
\text { mum }\end{array}$ & $\begin{array}{l}\text { Overall } \\
\text { Mean }\end{array}$ \\
\hline
\end{tabular}

Maximum

Maxim

$0.629^{2}$

$\begin{array}{cc} & 0.767^{2} \\ 0.616^{2} & 0.819^{4}\end{array}$

$0.810^{4}$

0.9394

Mean

Maximum

$0.616^{2} \quad 0.819^{4}$

$0.843^{4} \quad 0.954^{4}$

Table III The relationship between maximum resting high pressure zone pressure and amplitude of postdeglutitive high pressure zone contractions ${ }^{1}$

${ }^{1}$ Figures indicate the correlation coefficient, $r$.

${ }^{2} \mathrm{P}<0.05 ;{ }^{3} \mathrm{P}<0.01$; $\mathrm{P}<0.001$

Explanations for 'max. mean' and 'mean max.' are in the text.

'Overall mean' indicates that, for each subject, the mean value for all high pressure zone post-deglutitive contractions was taken. expressed in relation to the upper border of the high pressure zone (which was $0.5-2.5$, mean $1.18 \mathrm{~cm}$ proximal to the pressure inversion point), are shown in Table IV. Transient falls in $p \mathrm{H}$ shortly after deglutition were regularly observed. These generally lasted approximately five to 10 seconds, and began approximately two seconds after deglutition. Hence they coincided with the phase of relaxation of the high pressure zone. The frequency of these responses diminished as the recording assembly was withdrawn towards the oesophagus (Table IV). An illustrative record is shown in Figure 4. The mean values for the most proximal levels at which a $p \mathrm{H}$ response occurred were $0.62 \mathrm{~cm}$ (range $-1 \cdot 5-+3 \cdot 5$ ) distal to the pressure inversion point, and $1.7 \mathrm{~cm}$ (range $-0.5-+4.5)$ distal to the upper border of the high pressure zone.

\section{Discussion}

The findings from this study, obtained by infused

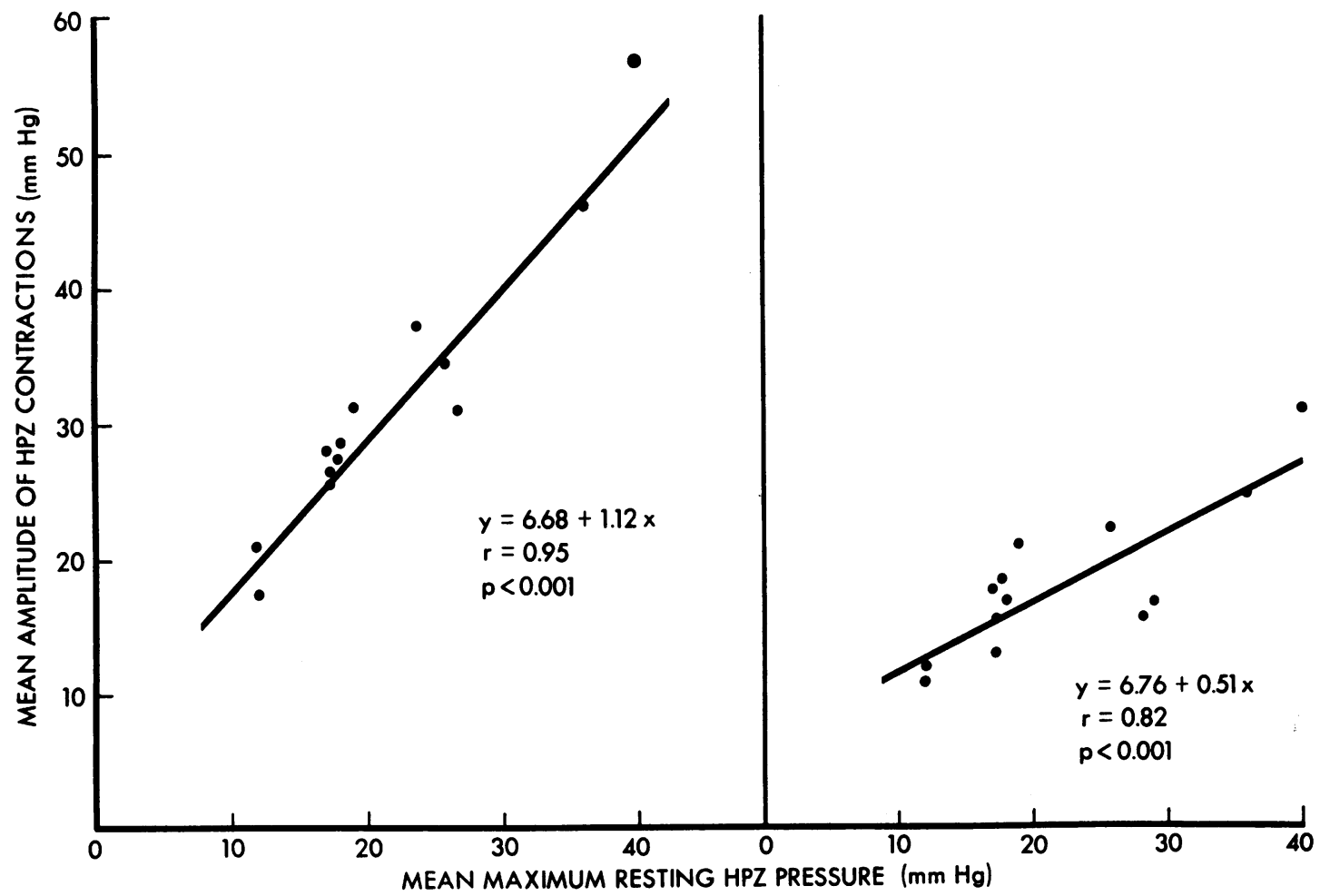

Fig. 3 The relationship between maximum resting high pressure zone pressure and mean amplitude of contractions. In the plot on the left, the amplitude of contractions has been expressed in relation to gastric baseline pressure, while in the right-hand plot, amplitude was measured in relation to the resting pressure at a given level immediately before deglutition. 


\begin{tabular}{|c|c|c|c|c|c|c|c|c|c|c|c|c|c|c|}
\hline $\begin{array}{l}\text { Distance from upper border of high } \\
\text { pressure zone }(\mathrm{cm})\end{array}$ & 5 & 4.5 & 4 & 3.5 & 3 & 2.5 & 2 & 1.5 & 1 & 0.5 & 0 & -0.5 & -1 & -1.5 \\
\hline Resting $p \mathrm{H}^{2}$ & $1 \cdot 76$ & $2 \cdot 15$ & $2 \cdot 47$ & 2.92 & $3 \cdot 50$ & 3.94 & $4 \cdot 28$ & $4 \cdot 42$ & $4 \cdot 62$ & $4 \cdot 82$ & $5 \cdot 10$ & $5 \cdot 23$ & $5 \cdot 45$ & 5.54 \\
\hline $\begin{array}{l}\text { Frequency of } p \mathrm{H}^{3} \text { fall after } \\
\text { deglutition }(\%)\end{array}$ & 78 & 89 & 50 & 91 & 75 & 77 & 52 & 62 & 31 & 15 & 15 & 10 & 0 & 0 \\
\hline
\end{tabular}

Table IV pH measurements on stepwise withdrawal of electrode through high pressure zone

${ }^{1}$ Measurements expressed in relation to upper border of high pressure zone. A negative value $(-)$ indicates a point proximal to this level. ${ }^{2}$ Mean values, 13 subjects

${ }^{\mathrm{s}} \mathrm{pH}$ fall' indicates a transient postdeglutitive fall in $p \mathrm{H}$ coincident with relaxation of high pressure zone.
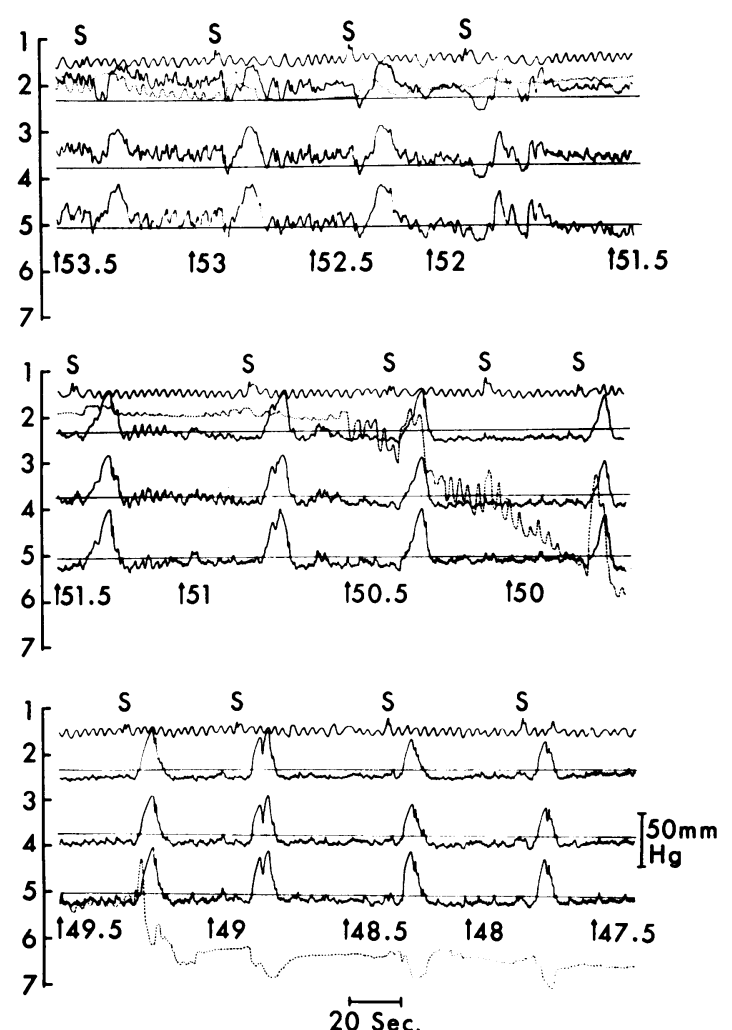

Fig. 4 Tracing to illustrate sphincteric $\mathrm{pH}$ changes in response to swallowing.

As in Figure 2, the upper trace is a pneumograph, and the three lower traces are pressure records from perfused catheters whose openings are at the same axial level. The numbers denote distances, in centimetres, between the $\mathrm{pH}$ electrode and the incisors. The pressure recording openings are $5 \mathrm{~cm}$ proximal to the electrode. The dotted line repsents $\mathrm{pH}$, with the $\mathrm{pH}$ scale being shown on the left of the figure.

Transient falls in $\mathrm{pH}$ shortly after deglutition are clearly seen between 50.5 and $49 \mathrm{~cm}$. Note that the subject swallowed twice with the $\mathrm{pH}$ electrode at $50.5 \mathrm{~cm}$. The first swallow, followed by an oesophageal contraction, was associated with a transient $\mathrm{pH}$ fall. The second swallow did not evoke an oesophageal response, and was not associated with any significant $\mathrm{pH}$ change.

The lower border of this subject's high pressure zone was at $50.5 \mathrm{~cm}$. catheter measurements, are essentially similar to those reported by Kelley et al (1960) who studied normal deglutitive responses of the high pressure zone by means of uninfused catheters and a miniature balloon-covered transducer in situ. Thus, in health, relaxation is a progressive pressure change which passes in a caudad direction through the high pressure zone, and which does not occur simultaneously throughout the whole of the latter. Contraction, likewise, progresses in a peristaltic fashion through the high pressure zone, as through the non-sphincteric oesophagus. The sequential nature of these pressure changes, though predictable on a priori grounds since the lower oesophageal sphincter is but a specialized part of the oesophagus as a whole, does not appear to have been adequately stressed. Ideally, it is necessary to assess the regularity, the timing, and the amplitude of responses to deglutition at all levels within the high pressure zone before reaching a conclusion regarding the normality or otherwise of sphincteric function. Observations of the occurrence of relaxation and contraction within the high pressure zone during the course of a manometric study may not of themselves exclude the possibility of abnormal sphincteric behaviour. It is possible that failure to make a detailed analysis of all aspects of sphincteric responses may result in lack of recognition of subtle but clinically significant deviations from normality. It is of interest to note that, as measured from a standard baseline, pressures generated during contraction were higher in the high pressure zone than in the distal oesophagus, which serves to underline the importance of the temporal relationship between pressure changes in the high pressure zone and those occurring more proximally. As Fleshler (1967) has stressed in another context, the gradient of pressure between various oesophageal levels is the chief determinant of the efficacy of oesophageal propulsion.

All subjects in this study showed high pressure zone contractions at sites distal to the pressure inversion point. The discrepancy between these observations and those of Kelley et al (1960), who rarely observed contractions below the pressure inversion point, may, in part at least, be related to the more proximal location of the pressure inversion 
point with infused as opposed to uninfused catheters (Winans and Harris, 1967; Harris and Pope, 1966).

In agreement with Kelley et al we noted that throughout the phase of relaxation a small pressure barrier was maintained in the high pressure zone between stomach and oesophagus. One may conclude therefore that the lumen within the high pressure zone during relaxation in response to a 'dry' swallow is normally smaller than the recording assembly used in this study (diameter $0.5 \mathrm{~cm}$ ). The probable existence of a small residual sphincteric pressure during relaxation, considered in conjunction with the peristaltic nature of the latter, might lead one to anticipate that gastroesophageal competence is retained during the cycle of postdeglutitive events within the high pressure zone. The $\mathrm{pH}$ changes in relation to swallowing, as determined in this study, tend to support this possibility. Thus, although all subjects showed brief falls in $p H$ shortly after deglutition in the more distal parts of the high pressure zone, the frequency with which such falls occurred decreased sharply as the $p H$ electrode was withdrawn proximally. The most proximal level at which a postdeglutitive fall in $p \mathrm{H}$ occurred was, on average, $1.7 \mathrm{~cm}$ below the upper border of the high pressure zone, and $0.6 \mathrm{~cm}$ below the pressure inversion point. These observations indicate that, under these experimental conditions at least, the integrated sequence of dynamic events within oesophagus and high pressure zone prevents the reflux of gastric contents into the lower oesophagus. On the other hand, it would appear that a certain length of the high pressure zone, which varies somewhat from one individual to another, is in health regularly bathed with gastric juice for a brief period after swallowing. Since the exact anatomical relationship between the gastroesophageal mucosal junction and the manometrically delineated high pressure zone was not defined in these subjects, the significance of this phenomenon vis à vis exposure of oesophageal mucosa to gastric contents is unclear. In any event, subjects were studied in the recumbent position, and falls in $p \mathrm{H}$ after deglutition were transient.

All measurements, both of pressure and of $p \mathrm{H}$, were made after the intragastric instillation of at least $150 \mathrm{ml}$ of $0.1 \mathrm{~N} \mathrm{HCl}$. It is likely, therefore, that circulating gastrin levels were low (Oberhelman, Woodward, Zubiran, and Dragstedt, 1952), though resting sphincteric pressures, which varied between 12 and $40 \mathrm{~mm} \mathrm{Hg}$, were all within the normal range. Under these circumstances a significant correlation was found to exist between the maximum resting sphincteric pressure and the force of sphincteric contraction in response to swallowing. This relationship, which perhaps may not apply in situations where circulating gastrin levels are high, suggests that in health a sphincter which is strong by one criterion is strong also by another. It is relevant to the concepts of 'hypertensive' (Code, Schlegel, Kelley, Olsen, and Ellis, 1960; Ellis, Code, and Olsen, 1960) and 'hyperreacting' (Code et al, 1960) lower oesophageal sphincters. Neither of these terms has been adequately defined. The designation of 'hypertensive' was applied by Code et al (1960) to the sphincters of a group of individuals whose maximum sphincteric pressures were at the upper end of the spectrum observed in a large and miscellaneous collection of patients referred for diagnostic oesophageal motility studies; that is to say, the diagnosis of excessive resting sphincteric pressure was not based upon comparison with measurements obtained in a normal healthy population. Moreover, sphincters that were hypertensive by one method (unperfused catheter) were not often hypertensive by another (balloon-covered miniature transducer) and vice versa. It was further noted that 'hypertensive' sphincters often contracted with 'excessive vigour', in which cases they were denoted to be 'hyperreacting'. This combination of apparent abnormalities suggests that the 'hypertensive' sphincter could, in some cases, represent one extreme of the normal range. A rational choice between this and other alternatives cannot be made on the basis of information presently available.

Postdeglutitive contractions in the high pressure zone are considerably more prolonged than those in the non-sphincteric oesophagus. In this study, the mean duration of 171 analysable sphincteric contractions was 13 seconds. The duration of the longest recorded contraction varied between 13.8 and 33.0 seconds in the 13 subjects. In view of these findings, the criteria proposed by Garrett and Godwin (1969) for the diagnosis of 'hypercontracting' sphincter would appear open to question. These authors stated that their normal upper limit for duration of sphincteric contractions was 8.5 seconds. They selected, from a group of 381 patients referred for diagnostic motility studies, 11 whose sphincters showed, in their judgement, excessively prolonged contractions. Sphincteric characteristics in this group were retrospectively compared with those of 10 normal subjects. On the basis of an analysis of approximately two contractions for each individual, they claimed that the two groups differed significantly. It is pertinent to note that the mean duration of sphincteric contractions in the normal subjects here reported was greater (by about 2.5 seconds) than in their 'hypercontracting' group, and approximately twice as great as in their normal group. An important methodological difference between the two studies, namely, continuous infusion of recording 
catheters, may to some extent contribute to these discrepancies.

It seems likely that events within the lower oesophageal sphincter are no less important in symptom pathogenesis than those in the nonsphincteric oesophagus above it, for integration of function within the two areas is essential for normal transport of a bolus from mouth to stomach. In this context, a contraction which is (excessively) powerful but coordinate almost certainly has less clinical significance than one which is relatively weak but incoordinate. Undue emphasis appears to have been placed on the absolute dimensions of pressure events within the high pressure zone, as opposed to their sequential spatial relationships. While it is not disputed that there are patients whose sphincteric resting pressure is excessive, and whose sphincteric contractions are abnormally vigorous, or abnormally prolonged, or both, it would appear that further extensive studies in large numbers of healthy people are necessary before such departures from normality can be accurately defined. Moreover, unless and until a standard and generally accepted technique for oesophageal manometry is available, the universal adoption of any one set of criteria will be inappropriate.

This study was supported in part by grant AM 05122 from the National Institutes of Health.

The authors are grateful to Gary Zerbe, MS, for the statistical analyses.
References

Atkinson, M., Edwards, D. A. W., Honour, A. J., and Rowlands, E. M. (1957). Comparison of cardiac and pyloric sphincters. A manometric study. Lancet, 2, 918-922.

Botha, G. S. M., Astley, R., and Carre, I. J. (1957). A combined cineradiographic and manometric study of the gastroesophageal junction. Lancet, 1, 659-662.

Code, C. F., and Schlegel, J. F. (1958). The pressure profile of the gastroesophageal sphincter in man: an improved method of detection. Proc. Mayo Clin., 33, 406-414.

Code, C. F., Schlegel, J. F., Kelley, M. L., Jr., Olsen, A. M., and Ellis, F. H., Jr. (1960). Hypertensive gastroesophageal sphincter. Proc. Mayo Clin., 35, 391-399.

Ellis, F. H., Jr., Code, C. F., Olsen, A. M. (1960). Long esophagomyotomy for diffuse spasm of the esophagus and hypertensive gastroesophageal sphincter. Surgery, 48, 155-169.

Fleshler, B. (1967). Diffuse esophageal spasm. Gastroenterology, 52, 559-564.

Fyke, F. E., Jr., Code, C. F., and Schlegel, J. F. (1956). The gastrooesophageal sphincter in healthy human beings. Gastroenterologia (Basel), 86, 135-150.

Garrett, J. M., and Godwin, D. H. (1969). Gastroesophageal hypercontracting sphincter. J. Amer. med. Ass., 208, 992-998.

Harris, L. D., and Pope, C. E., II. (1966). The pressure inversion point: its genesis and reliability. Gastroenterology, 51, 641-648.

Kaye, M. D., and Showalter, J. P. (1971). The manometric configuration of the lower esophageal sphincter in normal human subjects. Gastroenterology, 61, 213-223.

Kelley, M. L., Jr., Wilbur, D. L., III, Schlegel, J. F., and Code, C. F. (1960). Deglutitive responses in the gastroesophageal sphincter of healthy human beings. J. appl. Physiol., 15, 483-488.

Oberhelman, H. A., Jr., Woodward, E. R., Zubiran, J. M., and Dragstedt, L. R. (1952). Physiology of the gastric antrum. Amer. J. Physiol., 169, 738-748.

Pert, J. H., Davidson, M., Almy, T. P., and Sleisenger, M. H. (1959). Esophageal catherization studies. I. The mechanism of swallowing in normal subjects with particular reference to the vestibule (esophagogastric sphincter). J. clin. Invest., 38, 397. 406.

Pope, C. E., II. (1967). A dynamic test of sphincter strength: its application to the lower esophageal sphincter. Gastroenterology, 52, 799-786.

Winans, C. S., and Harris, L. D. (1967). Quantitation of lower esophageal sphincter competence. Gastroenterology, 52, 773778. 